\title{
Gambaran Karakteristik Petugas Pendistribusian Berkas Rekam Medis Rawat Jalan Di UPT Rumah Sakit Khusus Paru Tahun 2019
}

\author{
Ali Sabela Hasibuan \\ Program Studi D-III Perekam dan Informasi Kesehatan, Universitas Imelda Medan
}

\begin{tabular}{l}
\hline Article Info \\
\hline Article history: \\
Received August 29, 2020 \\
Revised August 30, 2020 \\
Accepted August 31, 2020 \\
\hline
\end{tabular}

Keywords:

Distribution

Medical Records

Outpatient

\begin{abstract}
Distribution is the process of distributing products from producers to the hands of the public or consumers. The ease with which consumers get the desired product is the top priority of every company to satisfy its customers. In a distribution system, the route chosen is the most important element in determining the distance to be traveled and the costs that must be incurred. If the selected route is optimal, the distribution system will be more effective and efficient because it will pass a route with a minimum distance, so the elements that involve distance are also minimal, such as transportation costs, travel time, the level of pollution produced, and energy expended. The purpose of this study was to determine the distribution of outpatient medical record files at the UPT Special Hospital for the Lung Year 2019. This study used a descriptive research method with the aim of making an objective description or descriptive of a situation. The research site was conducted at the Special Hospital for Lung in 2019 with a total population of all medical record officers, namely 5 people and the sampling technique in this study was total sampling with the characteristics of all medical record officers. So the researchers analyzed the data starting from editing, coding, sorting, data entry, cleaning. The results of the study based on the majority of high school education were 3 people (60\%) minority DIII medical records as many as 1 person (20\%) and S1 education as many as 1 person (20\%), based on the majority of 1-5 years working duration as many as 3 people (60\%), and a minority of 6-10 years of work as many as 2 people $(40 \%)$. So it can be concluded that the characteristics of medical record officers in the most recent pulmonary hospital are 3 people (60\%).
\end{abstract}

This is an open access article under the CC BY-SAlicense.

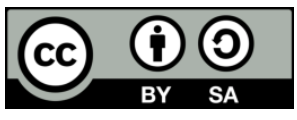

\section{Corresponding Author:}

Ali Sabela Hasibuan,

Program Studi D-III Perekam dan Informasi Kesehatan,

Universitas Imelda Medan,

Jl. Bilal No. 52 Kelurahan Pulo Brayan Darat I Kecamatan Medan Timur, Medan - Sumatera Utara.

Email: alisabelahasibuan@gmail.com

\section{PENDAHULUAN}

Menurut Peraturan Menteri Kesehatan Republik Indonesia No. 1204/Menkes/SK/X/2004 tentang Persyaratan Kesehatan Lingkungan Rumah Sakit, dinyatakan bahwa: "Rumah sakit merupakan sarana pelayanan kesehatan, tempat 
berkumpulnya orang sakit maupun orang sehat, atau dapat menjadi tempat penularan penyakit serta memungkinkan terjadinya pencemaran lingkungan dan gangguan kesehatan".

Dari pengertian diatas, rumah sakit melakukan beberapa jenis pelayanan diantaranya pelayanan medik, pelayanan penunjang medik, pelayanan perawatan, pelayanan rehabilitasi, pencegahan dan peningkatan kesehatan, sebagai tempat pendidikan dan atau pelatihan medik dan para medik, sebagai tempat penelitian dan pengembangan ilmu dan teknologi bidang kesehatan serta untuk menghindari risiko dan gangguan kesehatan sebagaimana yang dimaksud, sehingga perlu adanya penyelenggaan kesehatan lingkungan rumah sakit sesuai dengan persyaratan kesehatan.

Menurut PERMENKES No: 269/MENKES/PER/III/2008 yang dimaksud rekam medis adalah berkas yang berisi catatan dan dokumen antara lain identitas pasien, hasil pemeriksaan, pengobatan yang telah diberikan, serta tindakan dan pelayanan lain yang telah diberikan kepada pasien.

Salah satu bentuk pelayanan rawat jalan di rumah sakit adalah pendistribusian berkas rekam medis. Distribusi adalah suatu proses penyampaian barang atau jasa dari produsen ke konsumen dan para pemakai, sewaktu dan dimana barang atau jasa tersebut diperlukan. Untuk mendukung pelayanan yang baik maka waktu pendustrian berkas rekam medis harus sesuai dengan standar yang telah ditetapkan oleh pemerintah. Standar pelayanan pendistribusian ini dapat menunjang kepuasan pasien dalam pelayanan yang diberikan rumah sakit kepada pasien (UGM, 2014).

Menurut (Rustiyanto, 2009) rekam medis adalah keterangan baik yang tertulis maupun yang terekam tentang identitas, anamnese penentuan fisik laboratorium, diagnosa segala pelayanan dan tindakan medik yang diberikan kepada pasien dan pengobatan baik yg dirawat inap, rawat jalan maupun yang mendapatkan pelayanan gawat darurat.

Di RSUD Dr. Sardjito Yogyakarta khususnya pada bagian distribusi bahwa dalam penyediaan dan pengiriman berkas rekam medis untuk sampai ke poliklinik mengalami keterlambatan berdasarkan hasil data sekunder dari sistem informasi manajemen rumah sakit (SIMRS), berkas yang di distribusikan tidak 100\% sesuai dengan standar waktu pengirimannya yaitu berkas rekam medis $\leq 30$ menit.

Distribusi merupakan proses penyaluran produk dari produsen sampai ke tangan masyarakat atau konsumen. Kemudahan konsumen dalam mendapatkan produk yang diinginkan menjadi prioritas utama dari setiap perusahaan untuk memuaskan pelanggannya. Dalam sistem distribusi, rute yang dipilih merupakan elemen terpenting dalam menentukan jarak yang harus ditempuh dan biaya yang harus dikeluarkan. Jika rute yang dipilih optimal, maka sistem distribusi menjadi lebih efektif dan efisien karena akan melewati rute yang minimal jaraknya, sehingga elemen-elemen yang melibatkan jarak menjadi minimal pula, seperti biaya transportasi, waktu tempuh, tingkat polusi yang dihasilkan, dan energi yang dikeluarkan.

Berdasarkan penelitian (Paramita, dkk, 2009), dengan judul penelitian tinjauan pendistribusian dokumen rekam medis rawat jalan di rumah sakit umum daerah Dr. Soeroto ngawi Tahun 2009. Berdasarkan hasil penelitian diketahui bahwa pihak yang bertanggung jawab dalam melakukan pendistibusian dokumen rekam medis rawat jalan di RSUD Dr. Soeroto Ngawi adalah pasien secara langsung dan sudah sesuai dengan prosedur tetap rumah sakit. Pihak yang bertanggungjawab dalam pendistribusian dokumen rekam medis rawat jalan yaitu pasien secara langsung. Dalam pendistribusian dokumen rekam medis rawat jalan tanpa menggunakan buku catatan apapun. Pendistribusian dokumen rekam medis rawat jalan di RSUD Dr. Soeroto Ngawi untuk pasien umum, ASKES, JAMKESMAS tidak dilakukan oleh petugas TPPRJ melainkan dilakukan oleh pasien secara langsung antar unit pelayanan/poliklinik. 
Berdasarakan Survey awal yang dilakukan peneliti dengan melakukan wawancara kepada petugas rekam medis, menyatakan bahwa Tidak adanya petugas pendistribusian berkas rekam medis, Pasien yang langsung mendistribusikan berkas rekam medis, sehingga berkas rekam medis tidak sampai kepada poliklinik tujuan atau salah ruangan poliklinik. Berdasarkan permasalahan tersebut penulis tertarik untuk melakukan penelitian dengan judul "Gambaran Karakteristik Pendistribusian Berkas Rekam Medis Rawat Jalan Di UPT Rumah Sakit Khusus Paru Tahun 2019”.

\section{METODE PENELITIAN}

\section{A. Jenis Penelitian}

Jenis penelitian ini menggunakan metode penelitian deskriptif. Metode penelitian deskriptif adalah suatu metode penelitian yang dilakukan dengan tujuan untuk membuat gambaran atau deskriptif tentang suatu keadaan secara objektif. Metode penelitian deskriptif digunakan untuk memecahkan atau menjawab permasalahan yang sedang dihadapi pada situasi sekarang (Notoadmojo, 2010).

B. Sampel

Menurut Notoadmodjo, sampel adalah bagian dari objek yang diteliti yang dapat mewakili seluruh populasi tersebut. Teknik pengambilan sampel yaitu dengan Total Sampel. Tehnik Total Sampel yaitu jumlah seluruh pegawai rekam medis di UPT RS Khusus Paru sebanyak 5 orang.

C. Teknik Sampeling

Metode sampling yang digunakan untuk objek penelitian adalah Total Sampling.

D. Teknik Pengumpulan Data

Data pada penelitian ini diperoleh dari data primer dan sekunder. Data primer adalah data yang diperoleh secara langsung melalui wawancara dan observasi. Wawancara dilakukan dengan kepala Instalasi Rekam Medis dan petugas rekam medis di bagian pelaksanaan pendistribusian rekam medis rawat jalan. Observasi dilakukan untuk pengamatan terhadap lama waktu pelaksanaan pendistribusian berkas rekam medis rawat jalan. Data sekunder diperoleh dari profil UPT RS Khusus Paru (Sugiyono, 2012).

E. Variabel Penelitian

Variabel dalam penelitian ini adalah gambaran karakteristik petugas pendistribusian berkas rekam medis rawat jalan. Variabel yang dimaksud yaitu: jenis kelamin, pendidikan terakhir, umur, dan lama kerja.

\section{HASIL DAN PEMBAHASAN}

\subsection{Hasil}

Dari hasil penelitian yang dilakukan penulis mengenai "Gambaran Karakteristik Pendistribusian Berkas Rekam Medis Rawat Jalan Di UPT Rumah Sakit Khusus Paru Tahun 2019". Maka hasil yang diperoleh sebagai berikut:

Tabel 1. Distribusi Frekuensi Petugas Pendistribusian Berdasarkan Jenis Kelamin di Rumah Sakit Khusus Paru Medan Tahun 2019

\begin{tabular}{cccc}
\hline No & Jenis Kelamin & Frekuensi & Persentase (\%) \\
\hline 1 & Laki-laki & 3 & 60.0 \\
\hline 2 & Perempuan & 2 & 40.0 \\
\hline & Total & $\mathbf{5}$ & $\mathbf{1 0 0}$
\end{tabular}

Berdasarkan tabel di atas menunjukan bahwa mayoritas responden jenis kelamin Lakilaki adalah sebanyak 3 responden $(60.0 \%)$, sedangkan minoritas perempuan sebanyak 2 responden $(40.0 \%)$. 
Tabel 2. Distribusi Frekuensi Petugas Pendistribusian Bedasarkan Pendidikan Terakhir di Rumah Sakit Khusus ParuMedan Tahun 2019

\begin{tabular}{cccc}
\hline No & Pendidikan Terakhir & Frekuensi & Persentase (\%) \\
\hline 1 & SMA & 3 & 60.0 \\
\hline 2 & DIII & 1 & 20.0 \\
\hline 3 & S-1 & 1 & 20.0 \\
\hline & Total & $\mathbf{4}$ & $\mathbf{1 0 0}$
\end{tabular}

Berdasarkan tabel di atas menunjukan bahwa mayoritas responden berpendidikan SMA sebanyak 3 responden $(60.0 \%)$, sedangkan minoritas responden berdasarkan pendidikan D-III sebanyak 1 responden (20.0\%) dan S-1 berjumlah 1 responden $(20.0 \%)$.

Tabel 3. Distribusi Frekuensi Petugas Pendistribusian Berdasarkan Umur di Rumah Sakit Khusus Paru Medan Tahun 2019

\begin{tabular}{cccc}
\hline No & Umur (Tahun) & Frekuensi & Persentase (\%) \\
\hline 1 & $17-24$ & 2 & 40.0 \\
\hline 2 & $25-32$ & 3 & 60.0 \\
\hline & Total & $\mathbf{5}$ & $\mathbf{1 0 0}$
\end{tabular}

Berdasarkan tabel di atas menunjukan bahwa mayoritas responden yang berumur 17-24 Tahun sebanyak 2 responden (40.0\%), sedangkan minoritas responden yang berumur 25-32 tahun adalah sebanyak 3 responden $(60.0 \%)$.

Tabel 4. Distribusi Frekuensi Petugas Pendistribusian Berdasarkan Lama Kerja di Rumah Sakit Khusus ParuMedan Tahun 2019

\begin{tabular}{cccc}
\hline No & Lama Kerja (Tahun) & Frekuensi & Persentase (\%) \\
\hline 1 & $1-5$ & 3 & 60.0 \\
\hline 2 & $6-10$ & 2 & 40.0 \\
\hline 3 & $>10$ & - & - \\
\hline & Total & $\mathbf{5}$ & $\mathbf{1 0 0}$ \\
\hline
\end{tabular}

Berdasarkan tabel di atas dapat disimpulkan bahwa mayoritas lama kerja 1-5 tahun sebanyak 3 responden (60\%), sedangkan minoritas lama kerja 6-10 tahun sebanyak 2 responden $(40 \%)$.

Tabel 5. Distribusi frekuensi Petugas Pendistribusian Berkas Rekam Medis Rawat Jalan di Rumah Sakit Khusus ParuMedan Tahun 2019

\begin{tabular}{cccc}
\hline No & Kategori & Frekuensi & Persentase \\
\hline 1 & Baik & 2 & 40.0 \\
\hline 2 & Tidak Baik & 3 & 60.0 \\
\hline & Total & $\mathbf{5}$ & $\mathbf{1 0 0 \%}$ \\
\hline
\end{tabular}

Berdasarkan tabel di atas dapat disimpulkan bahwa kategori pelaksanaan pendistribusian berkas rekam medis rawat jalan di Rumah Sakit Khusus Paru masih tidak baik.

\subsection{Pembahasan}

Berdasarkan penelitian (Paramita, dkk, 2009), dengan judul penelitian tinjauan pendistribusian dokumen rekam medis rawat jalan di rumah sakit umum daerah Dr. Soeroto ngawi Tahun 2009. Berdasarkan hasil penelitian diketahui bahwa pihak yang bertanggung jawab dalam melakukan pendistibusian dokumen rekam medis rawat jalan di RSUD Dr. Soeroto Ngawi adalah pasien secara langsung dan sudah sesuai dengan prosedur tetap rumah sakit. Pihak yang bertanggungjawab dalam pendistribusian dokumen 
rekam medis rawat jalan yaitu pasien secara langsung. Dalam pendistribusian dokumen rekam medis rawat jalan tanpa menggunakan buku catatan apapun. Pendistribusian dokumen rekam medis rawat jalan di RSUD Dr. Soeroto Ngawi untuk pasien umum, ASKES, JAMKESMAS tidak dilakukan oleh petugas TPPRJ melainkan dilakukan oleh pasien secara langsung antar unit pelayanan/poliklinik. Berdasarkan hasil penelitian tentang Gambaran Karakteristik Pendistribusian Berkas Rekam Medis Rawat Jalan Di UPT Rumah Sakit Khusus Paru Tahun 2019 maka pembahasannya sebagai berikut:

\section{A. Petugas Pendistribusian Berdasarkan Jenis Kelamin}

Hasil penelitian mengenai karakteristik petugas pendistribusian rekam medis berdasarkan jenis kelamin yaitu laki-laki sebanyak 3 orang (60\%), perempuan sebanyak 2 orang $(40 \%)$. Pendistribusian berkas rekam medis harus dapat mendukung pelayanan kesehatan, khususnya pelayanan rawat jalan yang bermutu. Karena itu diperlukan lokasi penyimpanan dan petugas pendistribusian yang memadai agar pelayanan kesehatan dapat berjalan dengan baik dan lancar. (Ferlina Mauren, 2011).

\section{B. Petugas Pendistribusian Bedasarkan Pendidikan Terakhir}

Hasil penelitian mengenai petugas pendistribusian rekam medis berdasarkan pendidikan terakhir yaitu SMA sebanyak 3 orang (60\%), D-III sebanyak 1 orang (20\%), S1 sebanyak 1 orang (20\%). Berdasarkan hasil wawancara didapatkan bahwa tidak semua petugas pendistribusian dari lulusan D-III Rekam Medis sehingga pendistribusian tidak berjalan efektif dan efisien.

Menurut (Budiman dan Riyanto, 2013) faktor yang mempengaruhi pengetahuan: 1) Pendidikan, Proses perubahan sikap dan perilaku seseorang atau kelompok dan merupakan usaha mendewasakan manusia melalui upaya pengajaran dan pelatihan. Semakin tinggi pendidikan seseorang maka semakin cepat menerima dan memahami suatu informasi sehingga pengetahuan yang dimiliki juga semakin tinggi (Sriningsih, 2011).

\section{Petugas Pendistribusian Berdasarkan Umur}

Hasil penelitian mengenai petugas pendistribusian berdasarkan umur yaitu 17-24 tahun sebanyak 2 orang (40\%), 25-32 tahun sebanyak 3 orang (60\%). Menurut (Mubarak, 2007), beberapa faktor yang dapat mempengaruhi pengetahuan seseorang, diantaranya meliputi umur seseorang, tingkat pendidikan, pekerjaan, minat, pengalaman, serta sumber informasi.

\section{Petugas Pendistribusian Berdasarkan Lama Kerja}

Hasil penelitian mengenai petugas pendistribusian berdasarkan lama kerja yaitu 1-5 tahun sebanyak 3 orang (60\%), 6-10 tahun sebanyak 2 orang (40\%). Bagaimana cara menyelesaikan permasalahan dari pengalaman sebelumnya yang telah dialami sehingga pengalaman yang didapat bisa dijadikan sebagai pengetahuan apabila medapatkan masalah yang sama. Usia, Semakin bertambahnya usia maka akan semakin berkembang pula daya tangkap dan pola pikirnya sehingga pengetahuan yang diperoleh juga akan semakin membaik dan bertambah (Budiman dan Riyanto, 2013).

\section{E. Petugas Pendistribusian Berkas Rekam Medis}

Hasil penelitian mengenai petugas pendistribusian berkas rekam medis yaitu kategori baik sebanyak 2 orang (40\%), kategori tidak baik sebanyak 3 orang sebanyak 3 orang (60\%). Menurut (Gemala Hatta,) Rekam Medis merupakan kumpulan fakta tentang kehidupan seseorang dan riwayat penyakitnya, termasuk keadaan sakit, pengobatan saat ini 
dan saat lampau yang ditulis oleb para praktisi kesehatan dalam upaya mereka memberikan pelayanan kesehatan kepada pasien.

\section{KESIMPULAN}

Dari hasil penelitian yang berjudul "Gambaran Karakteristik Petugas Pendistribusian Berkas Rekam Medis Rawat Jalan di Rumah Sakit Khusus Paru" maka dapat disimpulkan:

1. Karakteristik petugas pendistribusian berkas rekam medis rawat jalan berdasarkan jenis kelamin yaitu berjenis kelamin laki-laki sebesar (60\%) dan berjenis kelamin perempuan sebesar (40\%).

2. Karakteristik petugas pendistribusian berkas rekam medis rawat jalan berdasarkan pendidikan terakhir yaitu berpendidikan SMA sebesar (60\%), berpendidikan DIII sebesar (20\%), dan berpendidikan S-1 sebesar (20\%).

3. Karakteristik petugas pendistribusian berkas rekam medis rawat jalan berdasarkan umur yaitu umur 17-24 tahun sebesar (40\%) dan umur 25-32 tahun sebesar (60\%).

4. Karakteristik petugas pendistribusian berkas rekam medis rawat jalan berdasarkan lama kerja yaitu 1-5 tahun sebesar (60\%) dan 6-10 tahun sebesar (40\%).

5. Karakteristik petugas pendistribusian berkas rekam medis rawat jalan mayoritas kategori tidak baik sebesar (60\%) dan minoritas kategori baik sebesar (40\%).

\section{REFERENCES}

Astaqauliyah, (2007). Makalah Pendistribusian. Dikutip Tanggal 29 maret 2019. Pukul 14.32 WIB http://Astaqauliyah.com

Budi, Savitri Citra. 2011. Manajemen Unit Kerja Rekam Medis. Yogyakarta: Quantum Sinergis Media.

Depkes, (2006). Pedoman Penyelenggaraan \& Prosedur Rekam Medis Rumah Sakit (Revisi II) Jakarta: Direktorat Jendral Bina Pelayanan Medik

Depkes, (2007), Standar Pelayanan Minimal Rumah Sakit.

Depkes RI Dirjen Yanmed. Pedoman Pengelolaan Rekam Medis Rumah Sakit di Indinesia. Jakarta : DepKes.2006.

Ery Rustiyanto, (2009). Etika Profesi Perekam Medis \& Informasi Kesehatan. Graha Ilmu: Yogyakarta.

Esaunggul, (2014). Makalah Pendistribusian. Dikutip Tanggal 01 maret 2019. Pukul 23.00 WIB. http://digilib.esaunggul.ac.id

Firzah, dika, (2015). Alur Pendistribusian. Dikutip Tanggal 05 maret 2019. Pukul 20.57 WIB. http://jmiki.aptirmik.or.id

Hurlock, E. B, (2002) Psikologi Perkembangan. 5thedition. Erlanga : Jakarta.

Kepmenkes RI. 2007. Keputusan Menteri Kesehatan Republik Indonesia Nomor 377 Tahun 2007 Tentang Standar Profesi Perekam Medis Dan Informasi Kesehatan. Diakses dari: www.depkes.go.id tanggal 10 Juni 2019.

Muninanjaya, (2004). Manajemen Kesehatan. EGC: Jakarta 
Notoatmodjo, S. (2003). Pendidikan dan perilaku kesehatan. Rineka Cipta. Jakarta

Notoatmodjo, (2010). Ilmu Perilaku Kesehatan. Rineka Cipta : Jakarta

Permenkes, (2010). Pengertian Rumah Sakit. Dikutip Tanggal 20 maret 2019. Pukul 15.00 WIB. http://kimbreyesung.com

Permenkes, (2008). No.269/MENKES/PER/2008 tentang Rekam Medis, Jakarta.

Retno, Andhika Rizky. (2015). SPO distribusi berkas rekam medis. Dikutip. Tanggal 25 maret 2019Pukul 22.45 WIB. http://eprintis.dinus/ac.id

Setiadi. (2007). Konsep dan Penulisan Riset Keperawatan Ed.I. Yogyakarta: Graha Ilmu.

Sugiyono. (2012). Metode Penelitian Kuantitatif, Kualitatif dan R\&D. Bandung: Alfabeta.

Sunny Ummul Firdaus. (2008). Rekam Medik Dalam Sorotan Hukum dan Etika. Surakarta.

\section{BIOGRAPHIES OF AUTHORS}

\begin{tabular}{|l|l|} 
Ali Sabela Hasibuan, Gelar D-III diperoleh dari Universitas Imelda Medan, Jurusan \\
Keperawatan pada Tahun 2008, Gelar Sarjana diperoleh dari Universitas Sari Mutiara \\
Medan Fakultas Keperawatan Tahun 2011, Magister Keperawatan diperoleh dari \\
Universitas Sumatera Utara, Jurusan Administrasi Keperawatan Tahun 2019. Saat ini \\
Aktif Sebagai Dosen Tetap di Prodi D-III Keperawatan Universitas Imelda Medan.
\end{tabular}

